УДК: $930.25 ; 398$

DOI: $10.33876 / 2311-0546 / 2020-51-3 / 49-56$

(C) В.И. Сподина

\title{
ФОЛЬКЛОРНОЕ НАСЛЕДИЕ ЮГРЫ: ОПЫТ АРХИВИРОВАНИЯ В ХХІ ВЕКЕ
}

В статье нашли отражение история и этапь исследования хантыйского фольклора с первой половины ХІХ в. по настоящее время. Впервые приводится характеристика современного периода изучения фольклора, сформулированная автором его периодизации Т.В. Волдиной. Отмечены особенности сбора и хранения различных жанров фольклора, учитывающие менталитет исполнителей, а также поставлены задачи, на которые следует обратить внимание учреждениям, ведущим сбор, хранение и изучение нематериального культурного наследия коренных малочисленных народов Севера.

Ключевые слова: фольклор, былички, ханты, манси, сакральные тексты, адаптация фольклорного сюжета, система электронного архивирования

Особенности культурной памяти как своеобразной символической формы передачи и актуализации культурных смыслов, приход в науку самих носителей традиционной культуры накладывают отпечаток на современные подходы к сбору и хранению фольклора коренных малочисленных народов Севера. Они проявляются в том, что произошёл отход от формализованной фиксации устного народного творчества к доверительному диалогу между «своими» - «своим» исследователем и «своим» информантом-исполнителем. Такая саморефлексия, изучение фольклора изнутри культуры, накладывает отпечаток на специфику методики его сбора и хранения.

Целенаправленно фольклор обских угров начал собираться с середины XIX в. в основном учёными Венгрии и Финляндии. Антал Регули во время своей экспедиции к северным хантам в 1843-1845 гг. в Берёзово записал первую остяцкую песню, текст которой открыл для него «высокую ценность остяцкой поэзии» (Папаи 1993: 26). Сказки южных (иртышских) хантов были собраны финским лингвистом А. Каннисто в период его поездки в Северо-Западную Сибирь в 1845 г. Фольклор был в центре внимания и другого финского исследователя А. Алквиста. Его материалы «стали первыми образцами хантыйского фольклора, появившимися в печати» (Волдина 2002: 23). В России первые краткие записи устного народного творчества ханты связаны с именем Н.А. Абрамова, который включил несколько преданий и легенд в этнографическое описание хантов Березовского края, вышедшее в 1858 г. (Абрамов 1858: 327-448). Сбор фольклора продолжается и в настоящее время усилиями учёных, работников культуры ХМАО-Югры.

Сподина Виктория Ивановна - д.и.н., главный научный сотрудник, БУ ХМАО-Югры «Обско-угорский институт прикладных исследований и разработок» (628011 ХантыМансийск, ул. Мира 14a). Эл. почта: vspodina@mail.ru. Spodina, Victoria I. - Dr. of Hist., Ob-Ugric Institute of Applied Research and Development (Khanty-Mansiysk, Russia). E-mail: vspodina@mail.ru 
Обстоятельное исследование Т.В. Волдиной, насчитывающее свыше ста имен собирателей устного народного творчества хантов, содержит авторскую периодизацию истории изучения хантыйского фольклора. Ею выделены следующие шесть этапов:

- первый этап (1840-1850-е годы) - начало изучения хантыйского фольклора, запись фольклорных текстов преимущественно венгерским учёным А. Регули;

- второй этап (1860-е годы - начало XX века) - сбор, расшифровка, публикации первоисточников, анализ фольклора как отечественными, так и зарубежными учёными;

- третий этап (начало XX века - 1920-е годы) - затухание собирательской деятельности, но активизация публикации ранних записей хантыйского фольклора;

- четвёртый этап (1930-1950 годы) - включение в собирательскую деятельность сотрудников Института народов Севера и представителей самого хантыйского народа;

- пятый этап (1960-1980-е годы) - сбор фольклора ведётся на хантыйском языке, главным образом, силами этнической интеллигенции (в основном, любителями) и первым хантыйским учёным Н.И. Терёшкиным, ведутся записи и публикации на русском языке Н.В. Лукиной и В.М. Кулемзиным;

- шестой этап (1991-2000 годы) - бурное развитие собирательской деятельности, исследование фольклора на научном уровне проводится учёными из числа коренных малочисленных народов Севера [Т.А. Молданова, Т.А. Молданов] (Волдина 2002: 183-184).

Реалии XXI в. позволили исследователю дополнить периодизацию ещё одним, седьмым (с 2000 г. по настоящее время), этапом. Т.В. Волдина связывает его «с качественным сдвигом в процессе дальнейшего изучения фольклора научными сотрудниками Обско-угорского института прикладных исследований и разработокносителями хантыйского языка, с системным подходом к изданию материалов фольклора, а также с его представлением в виртуальном пространстве сети Интернет» (Волдина 2020).

Накопленный массив фольклорных текстов, осознание этническим сообществом и органами государственной власти их огромной духовной ценности, потребности включения в региональный компонент образовательных программ материалов по традиционной культуре, привели к постановке задачи по систематизации собранного материала, созданию в местах компактного проживания хантов, манси и лесных ненцев фольклорных архивов и фондов. В 1991 г. образовался Белоярский архив северных хантов под руководством известного венгерского филолога Е.А. Шмидт. В 1993 г. по инициативе представителей этнической интеллигенции, ассоциации «Спасение Югры» и С.А. Поповой был создан фольклорный архив народа манси в районном центре Берёзово (рук. С.А. Попова), а в 1994 г. - Окружной научный архив (рук. Т.А. Молданова). В 2003 г. открылись ещё два фольклорных научных архива - сургутских хантов (рук. А.С. Сопочина) и Нижневартовский - по сбору фольклора лесных ненцев. Его возглавил Ю.К. Айваседа-Вэлло (Попова 2005: 9-10).

В настоящее время фольклор обских угров и самодийцев хранится в Обскоугорском институте прикладных исследований и разработок. В 1991 г. в его структуре был создан архивный отдел, который претерпел ряд преобразований (с 1994 г. - 
Научно-фольклорный отдел, с 1997 г. - Научно-фольклорный фонд, с 2009 г. Фольклорный отдел, с 2014 г. - Фольклорный центр). В его задачи входят: запись фольклорных текстов и образцов речи разных групп хантов, манси и ненцев, фиксация обрядов и праздников, систематизация материалов по культурному наследию коренных народов Югры, создание электронной базы данных по обско-угорскому фольклору. Такой подход позволил «поставить на высокий уровень хранение, учёт, популяризацию памятников устного народного творчества народов ханты и манси, использование архивных материалов в различных мультимедиа проектах» (Попова 2005: 16). За более чем четверть века сотрудниками института у 500 исполнителей записан фольклорный материал (около 4000 час. аудиозаписей на родных языках). Бо́льшую часть фольклорных текстов составляют личные песни, а также былички.

При записи фольклорных текстов учитываются как особенности традиционного мировоззрения исполнителей, так и их отношение к различным жанрам устного народного творчества. Например, былички про невероятные истории с «участием» НЛО (карты хоп 'железная лодка') следует записывать без намёков на вымысел и обязательно в речевой стилистике информанта. При фиксации «страшилок», чтобы настроить информанта «на нужную волну», собиратель вспоминает что-либо из зафиксированных ранее текстов. Рассказывать про пугающие существа информанты-женщины начинают не сразу, а «предпочитают незаметно положить рядом с собой какой-либо оберег (клык медведя), который находился в каком-либо швейном мешочке. При раскрытии образа невидимого существа они прибегают к жестикуляции, для того, чтобы вслух не произносить того, что касается внешних его характеристик. Например, ныне уже покойная Тарлина Дарья Григорьевна некоторые былички рассказывала шёпотом, пугающих существ называла иносказательно, чаще применяла указательное местоимение тумиелан - те» (Устное сообщение Е.Д. Каксиной, Белоярский, 2019).

При записи быличек следует фиксировать так называемые вводные фразы, которые важны для информанта: «чтобы этого никогда ни с кем не случилось», «чтобы никогда не наступило это время», «чтобы таких дней не было», «я никогда про эти случаи никому зря (как попало) не рассказываю», а также с пониманием относиться к пожилым исполнительницам, которые ещё и сейчас натягивают на лицо платок, прикрывая глаза от исследователя. Рассказывая былички исполнитель часто меняет темп рассказа (от быстрого к медленному) и силу звука (от громкого к тихому). Эти нюансы создают глубину ощущений, придают красочность и ритмику рассказу. Кроме того, информант, как правило, просит, чтобы эти рассказы слышал только один человек, что они не для массового слушателя, «как бы должны быть в тайне».

Чтобы сбор фольклорного материала был успешным, следует учитывать время суток, в которое планируется работа с носителем фольклора. «Все пугающие рассказы записываются днем, потому что вечером их рассказывать нельзя, так как информанты верят, что с наступлением сумерек пугающие существа их услышат, и за разглашение информации о них могут рассердиться и показаться на глаза, а это в свою очередь недобрый знак, предсказатель смерти. Иные информанты предпочитают вообще об этом не рассказывать, как бы собиратель не пытался их разговорить. Хотя другие жанры, сказки, личные песни производились ими без ограничений» (Устное сообщение Е.Д. Каксиной, Белоярский, 2019). 
Важно соблюдать требования к записи сакральных текстов, к категории которых относятся заговоры. Магические слова, содержащиеся в них, обладают, по поверьям обских угров, волшебной силой. Особо это касается заговоров, связанных с благополучием рода, со здоровьем отдельных членов семьи. Поэтому их слова не передаются, да и собиратели фольклора на этом не настаивают. В противном случае исполнитель лишится магического дара, а исследователь потеряет доверие исполнителя. Исключение составляют заговоры, «связанные с общим воздействием на окружающую среду, например, погоду и т.д.» (Ерныхова 2014: 131).

В настоящее время прослеживается тенденция расширения границ изучения фольклора. Публикуются исследования по городскому фольклору, школьному фольклору, семейным рассказам и др. Н.В. Новиков, один из ведущих отечественных сказковедов, считал, что нельзя ограничивать предмет фольклора исключительно наследием, а следует внимательнее изучать процессы рождения новых образцов народного искусства (цит. по ст.: Мельц 1997: 62). К таким «новым» образцам можно отнести современный детский фольклор. При этом важным аспектом записи фольклора является необходимость указания на обстановку, в которой он был записан. «Известно, что исполнение фольклорного произведения сказителем в чуждой социальной обстановке или общественно-исторической среде может стать причиной искажения и разрушения фольклорного текста, а это может привести к неправильной интерпретации, исторической недостоверности реконструкции породившей эпохи» (Ерныхова 2017: 72).

В качестве примера приведём сказку, сочинённую Кантеровым Кириллом (ханты, 8 лет) и записанную А.С. Сопочиной в 2016 г. в школе-интернате пос. Лямино Сургутского р-на.

- «Однажды жена с мужем живут в стареньком домике. У них дочь и сын. Мужчина пошёл на охоту. Дом у них не из брёвен построен, а сложен из старых палок. Мужчина построил дом из брёвен, окошко купил в магазине, люди дали ему деньги, было у него триста (рублей). Купил «Дружбу» (пилу), чтобы дом строить, топор сделал сам. Построил карали (загоны для оленей). А ещё $<\ldots>$ из досок кровать смастерил. Простыней у них не было, они постелили медвежью шкуру, спать очень тепло, вместо одеяла укрылись лисьей шубой. А ещё у них не было подушек. Отец пошел на охоту, добыл уток, их ощипали, перьями набили лисьи шкуры, края сшили, получились тёплые, мягкие подушки.

$<\ldots>$ На следующий день мужчина рано встал и пошёл на охоту. Шёл по болотистой местности и наткнулся на дома. В один из домов зашёл, это был двухэтажный дом. Он хорошенько изнутри осмотрел дом, как сделан, чтобы самому дома также строить. $<\ldots>$ И стоили эти дома очень дорого. Мужчина одному человеку дом построил и ему дали деньги. Одной женщине пекарню построил, также много денег дали. Потом построил два двухэтажных дома и ещё несколько домов, денег много получал и поэтому купил машину» (расшифровка и перевод А.Н. Волковой, 2019).

Этот пример показывает адаптацию фольклорного сюжета и образов к изменившейся социальной действительности. Очень метко по этому поводу заметил А.С. Каргин: «Пьесы Эврипида и Софокла, Шекспира и Мольера, 
Чехова и Островского - не более чем канва для многих поколений режиссеров и актеров. Каждый прочитывает и “оживляет” их по-своему; так же обстоит дело и с музыкальными произведениями. В реальном исполнении все они получают многовариантную трактовку, отражая современное этому исполнению понимание их смысла» (Каргин 1997: 25).

Важным направлением деятельности Фольклорного центра Обско-угорского института прикладных исследований и разработок является не только сбор, но и хранение фольклорных текстов, особенно содержащих магнитофонные записи. Известно, что срок хранения звука на аудио, видеопленке очень ограничен: со временем происходит слипание пленки, размагничивание, что приводит к исчезновению звука и изображения. Необходимость обеспечения сохранности звуковых фондов поставила задачу перевода звукового и аудиовизуального фонда на цифровые носители, с соблюдением всех международных стандартов, утвержденных Техническим комитетом Международной ассоциации звуковых и аудиовизуальных архивов, функционирующих под эгидой ЮНЕСКО. Звуковой фонд, приведённый в соответствие с едиными стандартами звукового архивирования, открывает возможности для включения фольклорных коллекций коренных малочисленных народов ХМАО-Югры в программу ЮНЕСКО «Память Мира» (Memory of the World).

С этой целью институтом был реализован проект по созданию электронного депозитария на базе музейно-информационной программы КАМИС. На каждую запись заводится учётная карточка, снабжённая научно-справочным аппаратом (данные об исполнителе, фольклорном тексте, авторе перевода и др.), что позволяет вести сквозной учет приема, выдачи материалов для изучения, обеспечивает быстрый поиск и получение различных справок, начиная от любой сказки и заканчивая биографиями информантов (рис. 1).

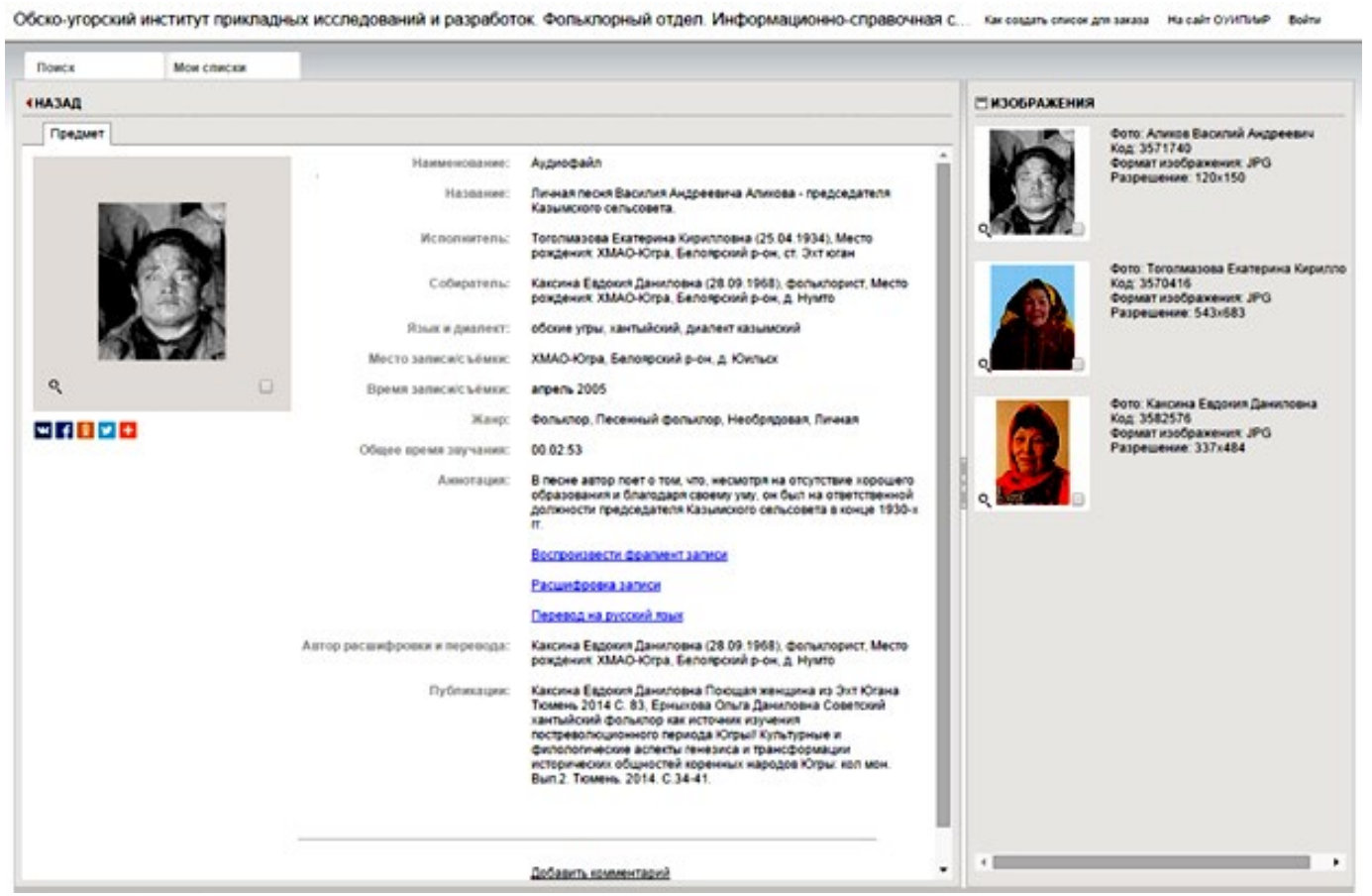

Рис. 1. Учётная карточка на фольклорную запись. 
Сотрудники Фольклорного центра эту электронную систему именуют уважительно КАМИС-аки. В хантыйской родственной терминологии слово аки обозначает «дядя». Это все старшие мужчины из рода отца/матери (старший брат отца или матери, сын старшего брата матери, если он старше матери). Ценностный статус дяди в традиционной культуре необычайно высок. Например, дух Вошаң ики называет себя «дядей всех юильских хантов» (Молданов 1999: 25). К богу грома и молнии Пӑдәң акєм «Гроза-дядя» ханты обращались с просьбой изменить погоду: «Дядя, твой водяной живот пусть в другом месте лопнет» (Акєм ики, йиңк хунэн па тӑхийн пєлки ат похан) (Пятникова 2008: 66). На уровне бытовых отношений среди хантов и ненцев зачастую можно услышать достаточно устойчивый фразеологизм, означающий выбор будущего дерева для изготовления обласа: «Вот растёт моя лодка, а рядом - лодка моего дяди» (Перевалова, Карачаров 2006: 24).

При обработке и хранении записей мы учитываем пожелания исполнителей, связанные с их символическим мышлением (запрет на размещение сакральных текстов, отдельное их хранение от записей других жанров и др.). Так, например, ссылаясь на волю исполнителей, некоторые тексты нами закрыты для использования на 20 лет (записи обрядов жертвоприношений, материал о людях, «которые делали гадости другим людям и что с ними затем происходит»). При обработке аудиокассеты исследователь делает лишь тезисное её описание, внося помету «далее кассету не прослушивала» и ставит свою подпись. «В этом случае, - отмечает О.Д. Ерныхова, можно говорить о том, что видеокассета или диск со священным материалом наделяется носителем фольклорной традиции сакральным смыслом и требует особого почитания и бережного хранения. По словам информантов, достаточно хранить подобные материалы выше уровня хранения остальных записей, а ещё лучше, если для них будет использован специальный шкаф, который также должен располагаться выше других шкафов» (Ерныхова 2014: 130). С таким же отношением к сакральным текстам столкнулся и автор настоящей статьи. При расшифровке ненецкой песни-обращения к Богу Солнца (Тяля-ңеңе) Ю.К. Айваседа-Вэлла сделал следующее замечание: «Такие песни нельзя “беспокоить” зря» (Песни реки Аган 2003: 45), в смысле прослушивать или исполнять.

Хотелось бы отметить, что проект «Электронный депозитарий по фольклору обских угров и самодийцев» (КАМИС) стал лауреатом премии за сохранение языкового многообразия «Ключевое слово» (2017), учреждённой Федеральным агентством по делам национальностей.

Таким образом, учёт особенностей этнического мировоззрения выдвигает перед фольклорной архивистикой задачу бережного подхода к информантам, актуализации методики сбора, обработки, перевода, хранения образцов фольклора, выработке стандартов фольклорного архивирования, правил доступа к материалам, находящимся в учреждениях, хранящих нематериальное культурное наследие коренных малочисленных народов Севера.

В марте 2019 г., на открытии Международного форума «Год языков коренных народов в России», Губернатор ХМАО-Югры Н.В. Комарова выступила с инициативой создания на основе депозитария по фольклору Обско-угорского института прикладных исследований и разработок Этнокультурного банка как международной площадки для широкого взаимодействия финно-угорских народов. В условиях перехода на цифровой способ связи, записи и передачи данных с помощью цифровых устройств, 
развития глобальной сети Интернет важно не потерять мировоззренческий аспект культурной памяти, сохраняемый традицией в XXI веке.

\section{Источники}

Абрамов 1858 - Абрамов Н.А. Описание березовского края // Тобольские губернские ведомости. 1858. № 19-25. С. 327-448.

Песни реки Аган 2003 - Песни реки Аган / запись текстов и примечания В.И. Сподина. Мегион-Варьёган: Инфорес Принт, 2003. 88 с.

Устное сообщение Е.Д. Каксиной, Белоярский, 2019.

Устное сообщение Т.В. Волдиной, Ханты-Мансийск, 2019.

\section{Научная литература}

Волдина Т.В. Хантыйский фольклор: история изучения. Томск: изд-во Том. ун-та, 2002. 258 с. Волдина T.B. Изучение хантыйского фольклора в Ханты-Мансийском автономном округе Югре в первые десятилетия XXI века // Вестник угроведения. 2020. Т. 10. № 3.

Ерныхова О.Д. К вопросу о проблемах сбора и обработки фольклора коренных малочисленных народов Югры (на материалах фольклорного архива Обско-угорского института прикладных исследований и разработок // Филологические исследования обско-угорских языков: традиции, новации, итоги, перспективы: Материалы Всероссийской заочной научно-практической конференции XII Югорские чтения (20 декабря 2013 г., ХантыМансийск). Тюмень: ФОРМАТ, 2014. С. 128-133.

Ерныхова О.Д. К вопросу о создании справочника носителей и исполнителей фольклора обских угров и лесных ненцев // Коренные малочисленные народы Севера, Сибири и Дальнего Востока: традиции и инновации. Материалы дистанционной научно-практической конференции XV Югорские чтения (20 дек. 2016 г. Ханты-Мансийск). Тюмень: ФОРМАТ, 2017. С. 70-79.

Каргин А.С. О фольклоре и фольклористике (полемические заметки) // Живая старина. 1997. № 4. С. 24-26.

Мельи М.Я. Николай Владимирович Новиков // Живая старина. 1997. № 3. С. 62.

Молданов Т.А. Картина мира в песнопениях медвежьих северных хантов. Томск: Изд-во Том. ун-та, 1999. $141 \mathrm{c.}$

Папаи Й. Памяти Антала Регули. Сургут: АИИК «Северный дом», 1993. 55 с.

Перевалова Е.В., Карачаров К.Г. Река Аган и её обитатели. Екатеринбург; Нижневартовск: УрО РАН; Студия «ГРАФО», 2006. $352 \mathrm{c}$.

Попова С.A. Деятельность Обско-угорского института прикладных исследований и разработок за 15 лет // Обские угры: научные исследования и практические разработки / сост. С.А. Герасимова. Ханты-Мансийск: Полиграфист, 2005. С. 8-19.

Пятникова T.P. Мифологическое представление о «верхнем мире»// Мифология хантов: материалы научно-практического семинара / сост. С.Н. Нестерова. Ханты-Мансийск: Полиграфист, 2008. С. 63-68.

\section{References}

Ernykhova, O.D. 2014. K voprosu o problemakh sbora i obrabotki fol'klora korennykh malochislennykh narodov Iugry (na materialakh fol'klornogo arkhiva Obsko-ugorskogo instituta prikladnykh issledovanii i razrabotok [On the Problems of Collecting and Processing Folklore of the Indigenous Peoples of Ugra (based on the materials of the folklore archive of the Ob-Ugric Institute of applied research and development]. In Filologicheskie issledovaniia obsko-ugorskikh iazykov: traditsii, novatsii, itogi, perspektivy: Materialy Vserossiiskoi zaochnoi nauchno-prakticheskoi konferentsii XII Iugorskie chteniia (20 dekabria 2013 g., 
Khanty-Mansiisk) [Philological research of the Ob-Ugric languages: traditions, innovations, results, prospects: Materials of the All-Russian correspondence scientific-practical conference XII Yugorsk readings], 128-133Tiumen: FORMAT.

Ernykhova, O.D. 2017. K voprosu o sozdanii spravochnika nositelei i ispolnitelei fol'klora obskikh ugrov i lesnykh nentsev [On the Issue of Creating a Directory of Speakers and Performers of Folklore of the Ob Ugric and Forest Nenets]. In Korennye malochislennye narody Severa, Sibiri i Dal'nego Vostoka: traditsii i innovatsii. Materialy distantsionnoi nauchno-prakticheskoi konferentsii XV Iugorskie chteniia (20 dekabria 2016 g. Khanty-Mansiisk) [ndigenous small peoples of the North, Siberia and the Far East: traditions and innovations. Materials of the distance scientific-practical conference XV Yugorsk readings (December 20, 2016, KhantyMansiysk)], 70-79. Tiumen': FORMAT.

Kargin, A.S. 1997. O fol'klore i fol'kloristike [About Folklore and Folklore Studies]. Zhivaia starina 4: 24-26.

Mel'ts, M.Ia. 1997. Nikolai Vladimirovich Novikov [Nikolay Vladimirovich Novikov]. Zhivaia starina 3: 62 .

Moldanov, T.A. 1999. Kartina mira v pesnopeniiakh medvezh 'ikh severnykh khantov [Picture of the World in the Chants of the Bear Northern Hunts]. Tomsk: izdatel'stvo Tomskogo universiteta.

Papai, I. 1993. Pamiati Antala Reguli [Memory Of Antal Reguli]. Surgut: AIIK "Severnyi dom".

Perevalova, E.V., and K.G. Karacharov. 2006. Reka Agan $i$ ee obitateli [Agan River and its Inhabitants]. Ekaterinburg; Nizhnevartovsk: UrO RAN; Studiia "GRAFO.

Popova, S.A. 2005. Deiatel'nost' Obsko-ugorskogo instituta prikladnykh issledovanii i razrabotok za 15 let [Activities of the Ob-Ugric Institute of Applied Research and Development for 15 Years]. In Obskie ugry: nauchnye issledovaniia i prakticheskie razrabotki [Ob Ugrians: scientific research and practical development], edited by S.A. Gerasimova, 8-19. KhantyMansiisk: Poligrafist.

Piatnikova, T.R. 2008. Mifologicheskoe predstavlenie o "verkhnem mire"” [Mythological Representation of the "Upper World"]. In Mifologiia khantov: materialynauchno-prakticheskogo seminara [Mythology of the Khanty: materials of the scientific and practical seminar], edited by S.N. Nesterova, 63-68. Khanty-Mansiisk: Poligrafist.

Voldina, T.V. 2002. Khantyiskii fol'klor: istoriia izucheniia [Khanty Folklore: History of Study]. Tomsk: izdatel'stvo Tomskogo universiteta.

Voldina, T.V. 2020. Izuchenie khantyiskogo fol'klora v Khanty-Mansiiskom avtonomnom okruge Iugre $\mathrm{v}$ pervye desiatiletiia XXI veka [Study of Khanty folklore in the Khanty-Mansiysk Autonomous Okrug - Yugra in the first decades of the XXI century]. Vestnik ugrovedeniia 10 (3).

Spodina, Victoria Ivanovna

\section{Folklore Heritage of Yugra: the experience of archiving in the XXI century}

The article reflects the history and stages of the study of Khanty folklore from the first half of the XIX century until now. The characteristic of the modern period of studying folklore, formulated by the author of its periodization T.V. Voldina, is published for the first time. The article discusses details of collecting and storing various folklore genres taking into account the mentality of performers, and highlights tasks for institutions that collect, store and study the intangible cultural heritage of indigenous peoples of the North.

Keywords: folklore, bailichkas, Khanty, Mansi, sacred texts, adaptation of the folk plot, the system of digital archiving 